\title{
Applying Salutogenesis in Organisations
}

\author{
Georg F. Bauer and Gregor J. Jenny
}

\section{Introduction}

A health-promoting setting is "the place or social context in which people engage in daily activities in which environmental, organisational, and personal factors interact to affect health and wellbeing' (WHO, 1998; emphasis ours). Several of the settings covered in Part V are more or less formalised organisations themselves, such as worksites, schools, universities and the military, whereas others are at least heavily influenced by organisations, such as cities, neighbourhoods or restorative environments. Thus, understanding how organisations influence health is crucial for promoting health in and through settings.

Organisations influence the health of society through three major paths: the health of their employees through working conditions, the health of their customers through the quality of their products or services and the population's health at large through their socio-ecological impact. This chapter focuses on the first path of organisations' impact on employee health through working conditions. It complements the chapter on salutogenic work by expanding the level of analysis to organisational characteristics. The chapter aims to be particularly applicable to for-profit organisations, in which it is exceptionally challenging to introduce a health agenda.

The chapter first introduces the key concept of organisational health development (OHD), as well as the changing economic and societal context with its implication for research and practice on OHD. Next, it reviews previous research on organisational health that is directly related to

This chapter is a revision and update of work published in Mittelmark, M.B., Sagy, S., Eriksson, M., Bauer, G., Pelikan, J.M., Lindström, B., \& Espnes, G.A. (eds). (2017). The Handbook of Salutogenesis. Springer, Cham. DOI: https://doi.org/10.1007/978-3-319-04600-6

G. F. Bauer $(\bowtie) \cdot$ G. J. Jenny

Center of Salutogenesis, Division of Public and Organizational

Health, Epidemiology, Biostatistics and Prevention Institute,

University of Zürich, Zürich, Switzerland

e-mail: georg.bauer@uzh.ch the salutogenic model or at least has a salutogenic orientation. Building on this background, the chapter presents our own OHD model that combines both a pathogenic and salutogenic path of health development. Further, the chapter shows how this OHD model is related to the salutogenic model and how it can guide salutogenic interventions in organisations. Finally, conclusions are drawn concerning future salutogenesis-based practice and research in organisations.

\section{Introducing the Key Idea of Organisational Health Development}

Fundamentally, this chapter relates to the EUHPID Health Development Model (Fig. 28.1; Bauer et al., 2006) as the underlying concept of individual health development. This model states that health is continuously developed through the interaction between individuals, their individual health determinants and their relevant living environments. This interaction can be characterised from a pathogenic perspective (risk factors $\Leftrightarrow$ ill health) and a salutogenic perspective (resources $\Leftrightarrow$ positive health). Following this model, organisations can be considered a key living environment and thus a significant contributor to both pathogenic and salutogenic health development.

Accordingly, we defined organisational health development $(O H D)$ as both the ongoing reproduction and the targeted improvement of health in organisations as social systems, based on the interaction (process dimensions) of individual and organisational capacities (structural dimensions) (Bauer \& Jenny, 2012, p. 135). In other words, ongoing OHD relates to all processes within the social system - the organisation - that have a salutogenic or pathogenic impact on individual health, whereas targeted OHD relates to optimisation processes that are explicitly aimed at improving the ongoing reproduction of individual health (Jenny \& Bauer, 2013).

In relation to the salutogenic model, a healthy organisation provides an environment that fosters job resources - 
Fig. 28.1 EUHPID health development model (Bauer et al. (2006). Reprinted by permission of Oxford University Press. (C) The Author (2006). All rights reserved. For Permissions, please email: journals. permissions@oup.com. This figure is not covered by Creative Commons license of this publication)

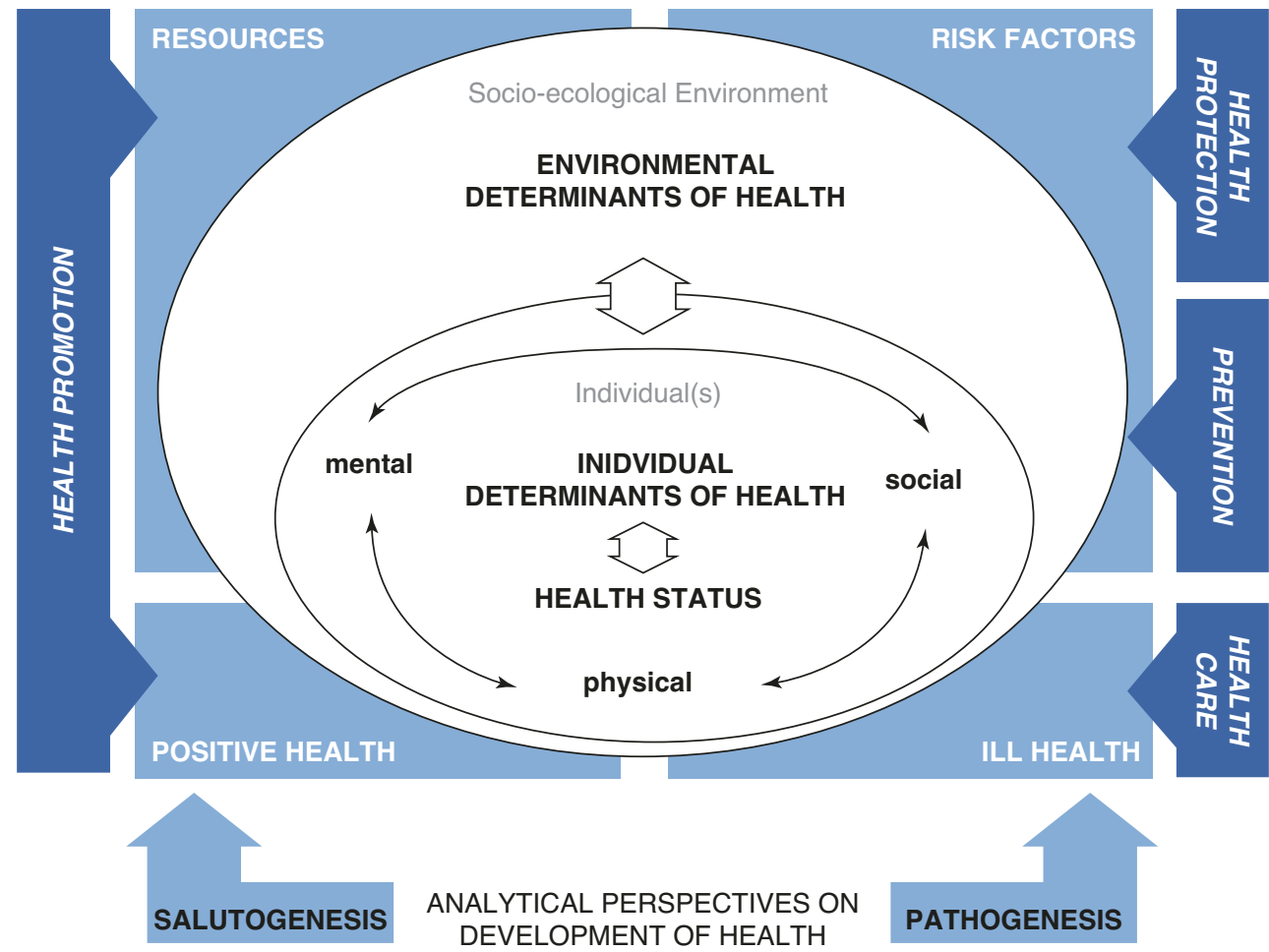

which can be viewed as generalised resistance resources (GRRs) - that lead to coherent work experiences, a general sense of coherence (SOC) and positive health (see the JD-R Health Model in Chap. 31 on carly, it keeps job demands - or stressors - within an acceptable range and as such reduces the risk of ill health in its employees. In short, a healthy or salutogenic organisation is low in producing pathogenic processes, but high in producing salutogenic processes - for both its human members and the whole organisation as a complex social system that vitally pursues its purpose.

\section{Context: The Growing Significance of Organisations for Health}

In most contemporary societies, we live and work in highly organised contexts. Throughout our lives, we directly encounter many different organisations as students, employees, volunteers and customers or are indirectly exposed to environmental damages caused by organisations. Thus, the salutogenic quality of these encounters becomes an ever more important determinant of population health.

On a societal level, research shows that during working age, a large proportion of inequalities in health can be explained by inequalities in working conditions. At the same time, people in lower job positions have limited opportunities to change their job if it is detrimental to their health. Organisations are under pressure of global competition and need to continuously adapt to a changing economic environ- ment. Such volatile organisations force employees to change jobs, their employer, or even their profession. This leads to weaker psychological contracts and less job security - the latter being a key resource for SOC, according to Antonovsky (1987a). The requirement of continuous flexibility is intensified by the digital transformation, which not only allows additional flexibility of working hours and working places but also demands continuous adaptations to new situations.

Job tasks and thus job characteristics have been shifting from primarily physical to psychosocial work processes. This implies new forms of 'exposures' to work-related threats and opportunities. At the same time, physical health and work ability are not sufficient prerequisites to fulfil such jobs. Instead, in a knowledge- and service-oriented economy, organisations expect their employees to display comprehensive biopsychosocial workability, agility, active work engagement and positive relations to customers.

These societal and organisational changes meet a changing workforce: increasingly well-educated employees demand more autonomy, self-defined flexibility, meaningful jobs supporting their self-fulfilment, opportunities for personal development and a good life domain balance. If these requirements are met, employees are more likely to remain in working life until retirement age - an urgent need in the face of an ageing society. This individual search for flexible and fulfilling work meets the increasing search for purposeorientation by organisations as a whole, that is, these individual and organisational needs come together in the recently 
emerging concept of purpose-driven organisations (Johnson et al., 2019).

\section{Implications for Practice and Research}

International health-promotion networks have been created for professional organisations providing public services including health-promoting schools, universities, cities and hospitals. These networks share that they follow a wholesystems approach. In for-profit organisations, health issues are addressed in more limited ways by legally required minimum standards for occupational safety and health and via worksite health-promotion networks largely focusing on traditional lifestyle-related health issues and individual workers' productivity. Although approaches such as the NIOSH 'total worker health' or the WHO healthy workplace model (WHO, 2010) aim to promote more integrative, comprehensive OHD approaches, their dissemination is limited because they face fragmented structures within organisations - with diverse stakeholders and specialists such as safety specialists, ergonomists, occupational physicians, case managers, occupational psychologists and human resource managers as well as traditional top-down power structures challenging participatory, empowering, employee-centred healthpromotion approaches (Bauer \& Hämmig, 2014).

At the same time, the VUCA context of organisations described above (i.e. their volatility, uncertainty, complexity, ambiguity) implies that the stable boundary conditions needed for static, legally required occupational health and safety systems and for more comprehensive approaches to workers' health are disappearing. As a reaction, organisations increasingly offer individual-level interventions focusing on health-related competencies and the self-responsibility of employees. As a complementary strategy, we could build the capacities of organisations to continuously self-observe and self-improve their impact on employees' health. This approach is at the core of this chapter and is expected to work well in unstable organisations with continuously changing workforce compositions. Developing such a capacitybuilding approach first requires a good understanding of how health continuously develops in organisations and what intervention approaches exist for targeted improvements.

\section{Organisational Health Research Explicitly Related to Salutogenesis}

Research on salutogenic health development in organisations has been focusing on the relationships between employeelevel working conditions and SOC in employees. This research is summarised in Chap. 31 on salutogenesis in the workplace and in Chap. 9 on SOC in this volume. In contrast, little conceptual and empirical research has examined broader, organisational-level factors in the context of salutogenesis. Some research at least addresses specific aspects of organisations (e.g. climate, leadership) in relation to salutogenesis or selected elements of the salutogenic model (e.g. SOC) in relation to organisations.

Antonovsky himself assumed that the type of organisation influences the degree of recognition an employee receives and the meaningfulness of his/her job (Antonovsky, 1987a). Feldt et al. (2000) showed that a good organisational climate and working for an organisation providing job security were strongly correlated with a strong SoC, which, in turn, was associated with well-being. Muller and Rothmann (2009) found that employees with low vs high SOC scores differed in their perception of so-called helping and restraining factors in organisations. Two studies found correlations between various leadership dimensions (e.g. organisational climate, supervisory support and teamwork), cultural beliefs and SOC (Cilliers \& Kossuth, 2002; Kossuth \& Cilliers, 2002). Other leadership studies found that leaders with high versus low SOC scores reported a better understanding of diversity management (Cilliers, 2011), a more positive attitude towards gender in organisations (Mayer \& van Zyl, 2013), and capacity for innovation management in organisations (Krafft, 2012). Eberz and Antoni (Eberz \& Herbert Antoni, 2016) introduced a systemic salutogenic interaction model that suggests examining how work-related SOC, attitudes and behaviours of leaders and employees interact in an organisation. Graeser (2011) developed an organisationbased SOC scale 'to identify potential salutogenic factors of a university as an organisation and workplace'. Building on Antonovsky's development of a family SOC (Antonovsky \& Sourani, 1988), she proposed a setting- or group-based SOC conceptualised as the interaction and transaction between the individual and the setting (e.g. family, community, organisation, school, university, workplaces, etc.)' (Graeser, 2011, p. 509). Following the dimensions of the general SOC, the university SOC scale assesses how far a university as a whole is perceived as comprehensible, manageable and meaningful. Cross-sectional analyses showed significant correlations with various disease symptoms in two university samples (Graeser, 2011).

\section{Broader Organisational Health Research Aligned with the Salutogenic Orientation}

Beyond this explicit salutogenic perspective, there exists much research on occupational and organisational health that considers organisational-level factors. During recent decades, this research has increasingly shifted away from a negative focus on stressors, stress, disorders and dysfunctioning to a positive focus on job and organisational-level 
resources and positive (health) outcomes. Examples are 'positive occupational health psychology' focusing on the employee level, 'positive organisational behaviour' linking individual, short-term, state-like outcomes to organisational factors and 'positive organisational scholarship' emphasising organisational, longer term outcomes (Bakker \& Derks, 2010; Bakker \& Schaufeli, 2008; Cameron et al., 2003; Day \& Randell, 2014; Gilbert \& Kelloway, 2014; Luthans \& Church, 2002; Nelson \& Cooper, 2008).

This positive perspective has been considered to be part of a larger movement towards positive aspects in social sciences including fields like positive psychology, community psychology, organisational development, appreciative inquiry, pro-social and citizenship behaviour as well as corporate social responsibility as 'other traditions with a focus on positive phenomena' (Cameron et al., 2003, p. 7). This list also exemplifies that the positive turn is accompanied by a trend to look beyond individual-level health resources by including a broad range of social and organisational determinants of health (see also Bennett et al., 2002; Hofmann \& Tetrick, 2003). Interestingly, this shift corresponds to Antonovsky's much earlier $(1979,1987 b)$ concern to look beyond individual risk factors by addressing overarching GRRs on any level, from the individual to the society at large. It also aligns well with the salutogenic orientation introduced in Chap. 3 of this volume.

\section{Previous Conceptualisations of Organisational Health}

In the search for a comprehensive model covering both pathogenic and salutogenic health development processes within the organisational context, we previously conducted a broad review of the conceptual literature covering the field of organisational health (development) (Bauer \& Jenny, 2012). We had structured this review into three aspects that are summarised here.

Organisational health 'outcomes': Based on 16 different earlier definitions of organisational health, Hofmann and Tetrick (2003) developed a two-dimensional integrative framework, distinguishing short- versus long-term health outcomes, as well as intrinsic versus extrinsic health goals. Referring to the literature of positive organisational behaviour and scholarship, Quick et al. (2007) introduced three superordinate categories of organisational health: leading a life of purpose, quality connections to others, positive self-regard and mastery. Based on this human-based conceptualisation, they suggest that an organisation itself can contribute to broader societal goals than pure effectiveness and economic performance. Similarly, sustainability (Hofmann \& Tetrick, 2003) or corporate social responsibility (Zwetsloot et al., 2008) were suggested as broader organisational health outcomes. Jaffe (1995) proposed that a company can be healthy for its own livelihood, its stockholders, employees, suppliers, customers, the community and its ecological environment.

Organisational health 'determinants': Role clarification, balance between job demands and resources, social relationships and support as well as dealing with change have been identified as key determinants of both individual (Bond et al., 2006) and organisational health (Kerr et al., 2009). Cotton and Hart (2003, p. 122) identified the organisational climate - defined as 'leadership and managerial practices, as well as the organisational structure and processes...' - as key determinants of organisational health. Also others proposed positive leadership (Luthans \& Church, 2002; Peiró \& Rodríguez, 2008; Quick et al., 2007) and organisational culture and climate (Shoaf et al., 2004) as key factors. The integrative AMIGO model (Peiró, 2000; Peiró \& Rodríguez, 2008) distinguishes hard (e.g. structure and technology) and soft facets of the healthy organisation (e.g. climate and management). The NHS (2009) review suggested interrelation, identity, autonomy and resilience as key components of organisational health (see also Kelloway \& Day, 2005).

Organisational health in complex social systems: Several authors moved beyond a linear determinant-outcome logic by considering organisations as complex, social systems (Bennett et al., 2002; DeJoy \& Wilson, 2003; Grawitch et al., 2006; NHS, 2009; Peiró \& Rodríguez, 2008), where interactions, reciprocal relationships and self-referential downward and upward spirals (Fredrickson, 2003; Fredrickson \& Dutton, 2008) are key for organisational health. Grawitch et al. (2006) proposed the 'Practices for the Achievement of Total Health (PATH)' model. This triangular model summarises the commonplace idea in the organisational health literature (cf. Hart \& Cooper, 2001) that organisational health interventions simultaneously promote the well-being of employees and of the organisation and that these two outcomes reinforce each other (see also the HERO model, Salanova et al., 2012). Besides this idea of harmonious win-win situations between individual-level and organisational-level health, several authors acknowledged possible tensions between intrinsic (employee-oriented) and extrinsic (company-oriented or societal) health-related interests. Hofmann and Tetrick (2003) proposed the joint optimisation of competing goals by applying a balanced scorecard (Kaplan \& Norton, 1996) as a 'strategiclevel model for organisational health' (p. 18).

\section{Emergence of the Organisational Health Development (OHD) Model Rooted in Salutogenesis}

Parallel to the organisational level, on the employee level the Job Demands-Resources (JD-R) model (Bakker \& Demerouti, 2007; Bakker \& Demerouti, 2017) has been established to show how working conditions and health are both negatively and positively related. As described in detail in Chap. 31, 'Applying 
Salutogenesis in the Workplace', this model implicitly incorporates both a pathogenic and salutogenic perspective. It distinguishes a health impairment process linking job demands to burnout from a parallel, motivational process linking job resources to work engagement. Also, the model includes crosscutting relationships between these processes and postulates that they co-produce (organisational) performance as an outcome important to organisations.

To link the JD-R model explicitly to the salutogenic model, and to make it applicable beyond mental health to physical and social health dimensions, we combined it with the logic of the general health development model (Bauer et al., 2006; Fig. 28.1). This resulted in the JD-R Health model (Brauchli et al., 2015), which labels the healthimpairment process as a 'pathogenic path' leading from job demands to negative health and the motivational process as a 'salutogenic path' leading more broadly from job resources to any positive health outcomes. Positive health is defined as physical, mental and social fulfilment, e.g. energetic fitness, joy and being embedded in positive relationships. As in the original JD-R model, we also assume cross-cutting relationships between the pathogenic and salutogenic path, and that they co-produce sustainable performance (see Fig. 28.2).

In order to add the management perspective to OHD, we complemented the above review on organisational health (Bauer \& Jenny, 2012) with a review of the literature on generic models of organisations, organisational change and management systems (Jenny \& Bauer, 2013). This resulted in a version of the OHD model that integrates the generic health development model (Bauer et al., 2006) with the New Management Model of St. Gallen (Rüegg-Stürm, 2003). The latter combines structuration theory (Giddens, 1984), a systemic viewpoint (Luhmann, 1984) and organisational ethics (Maak \& Ulrich,
2007). This OHD model depicts a social system where organisational capacities interact with individual capacities, from which factual, task-related processes (i.e. business, management and supporting processes) and social, people-related processes (i.e. leadership, relation and discourse processes) emerge (for details, see Jenny \& Bauer, 2013).

In a next step, we embedded the JD-R Health model into this version of the OHD model, resulting in the OHD model presented in Fig. 28.2. It depicts how the pathogenic and salutogenic processes result from an interaction between individual capacities (competency, motivation, identity) and organisational capacities (structure, strategy, culture) which are influenced by their respective individual (e.g. family life) and organisational (e.g. shareholders) environments. Further, it shows that interventions - ranging from more superficial optimisation to deep renewal - can target both the more stable individual and organisational capacities (as health-relevant structures) and the more dynamic job demands/resources (as health-relevant processes). The OHD model has been applied in both OHD research and practical interventions (Bauer \& Jenny, 2012; Jenny et al., 2011, 2014, 2020). It is in line with other propositions for salutogenic organisations and change put forward by a diverse group of international researchers (Bauer \& Jenny, 2013b).

\section{The OHD Model as a Specification and Expansion of the Salutogenic Model}

The OHD model permits a well-structured, theory-based application and specification of the salutogenic model to the context of organisations. Firstly, in the context of organisations, individual-level GRRs are specified as the individual
Fig. 28.2 Organisational health development (OHD) model. (Based on Bauer \& Jenny, 2012)
Organisational Environment

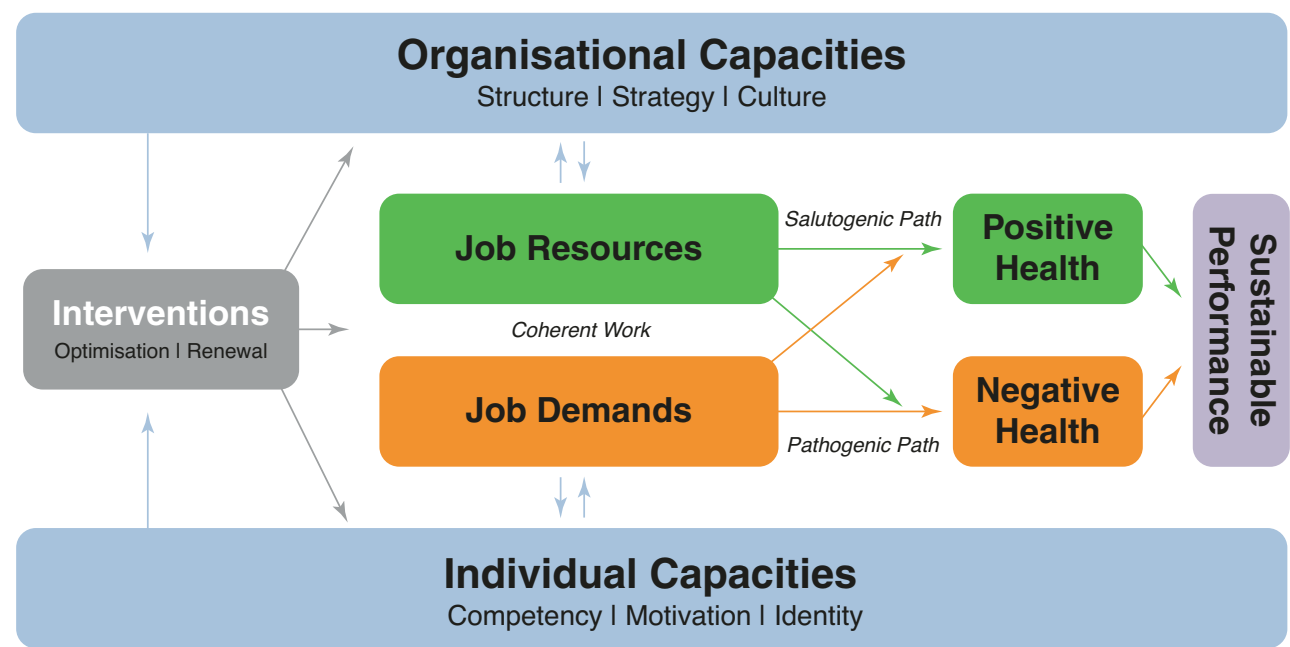

Individual Environment 
capacities of work-related competencies, motivation and identity. Organisational-level GRRs are detailed as capacities within the structure, strategy and culture of the organisation. Secondly, these individual- and organisational-level capacities interact to co-produce the work-processes in an organisation; in salutogenic terms, these work-processes can impose job demands (work-related stressors) or job resources (work-related GRRs) on employees. The relationship between job demands and job resources will influence how coherent we experience our work (see the concept of workrelated SOC in Chap. 31). All these relationships are influenced by and will influence the general SOC of employees, considered as an individual-level capacity of employees in the OHD model.

Besides these alignments with the original salutogenic model of Antonovsky (1979, 1987b), we also need to point out differences and expansions. We specify the term GRRs as job resources, individual capacities and organisational capacities as three levels of GRRs relevant in organisations. Further, we consider these resources not only as relevant for coping with and overcoming adversarial stressors (thus Antonovsky's original term 'resistance' resources) but also for pursuing own positive goals, personal growth and thus positive health development. Therefore, we omit the limiting term 'resistance' in relation to resources in our model.

Beyond the original single health continuum (ease/disease), we suggest distinguishing two orthogonally continua of negative and of positive health. Antonovsky defined the ease end of his ease-/dis-ease continuum still in a negative way, that is, the absence of pain, functional limitation, acute or chronic prognosis and health-related action implications (Antonovsky, 1987b). Thus, his original ease/dis-ease continuum is contained in the negative health box of our OHD model. To cover both negative and positive health experience, our model newly adds the concept of a positive health continuum covering concepts like well-being, wellfunctioning, self-fulfilment or pursuing one's purpose in life. This also implies that we do not limit the salutogenic path to the original coping path linking high (resistance) resources to moving to the ease-end of the ease-/dis-ease continuum (i.e. being low in negative health). Instead, we add an additional 'thriving' path directly linking high resources to developing positive health.

\section{State of Intervention Approaches to Improve Organisational Health}

The international literature reveals many practices for improving organisational health and groups them into diverse, inductively derived categories (see Bauer \& Jenny, 2012): For example, 'healthy workplace practices' addressing work-life balance, employee growth and development and employee involvement (Grawitch et al., 2006); 'approaches to organisational health' covering individual health promotion, job redesign and autonomous work groups (Shoaf et al., 2004); 'practitioner models' like health and productivity management, healthy culture planning and the healthy company (Bennett et al., 2002); 'leadership development' (Peiró \& Rodríguez, 2008; Quick et al., 2007); or 'self-assessment/adaptability' (Bennett et al., 2002, p. 72).

To better compare diverse intervention approaches to improve organisational health, we propose categorising them in reference to approaches distinguished in the field of human resource management (see Bauer \& Jenny, 2013a; Delery \& Doty, 1996; Grawitch et al., 2006):

- The universalistic approach: Practices that are effective regardless of the setting to which they are applied.

- The contingency approach: The effectiveness of an organisational practice is dependent on its consistency with other organisational components such as structure and strategy.

- The configurational approach: The total system of organisational practices needs to be improved to achieve a profound impact.

These deductively defined categories distinguish different types of relationships between an intervention and the organisation in which it is implemented. We previously applied these three approaches to OHD interventions as follows (for details, see Bauer \& Jenny, 2013a):

- Universalistic OHD: This approach aims for the fidelity of its own implementation and for reaching pre-defined outcomes. The intervention context (the organisation) is selected so that the intervention can be implemented with the least possible interference. The implementation process is pre-defined and standardised. The research objective is to produce evidence of the effectiveness of this standardised intervention.

- Contingency OHD: This approach focuses on the desired fit between a partly pre-defined intervention and the organisations in need of this intervention. Thus, the implementation process includes tailoring and fitting the content and process of the intervention to some degree to the context of the specific organisation in order to increase its acceptance and effectiveness. Research of this dynamic implementation process aims to understand under which conditions intervention outcomes can be achieved through multilevel (organisational) learning mechanisms.

- Configurational OHD: Finally, here the focus is the organisational 'figure' itself, that is, the system's configuration in terms of individual and organisational capacities that influence its members' health. The organisational context is not a mere boundary condition promoting, hin- 
dering or shaping the intervention, but the key target and actor of change. Thus, the content and process of the intervention will only emerge from this context and be co-created and owned by the organisation itself. The external change agent increasingly builds the capacity of the organisation for continuous self-improvement. Research will focus on this process of capacity-building, its impact on ongoing OHD and on its effect on the organisation's ability to purposefully go through similar optimisation processes in the future.

Evidently, a configurational OHD approach initially also requires some contingency or fitting to the organisation involved to assure a successful contracting. The contingency approach leaves open how deep it intervenes into the structures and processes of an organisation. However, it only evolves into a configurational intervention once it purposefully builds the capacity of organisations for future self-improvements.

A compilation of (salutogenic) OHD interventions (Bauer \& Jenny, 2013b) showed that the contingency approach sometimes combined with a configurational approach - is most prevalent in the field. Here, the one-size-fits-all approach has been replaced by adaptive intervention designs applying variations of participatory problem-solving cycles (cf. Henning \& Reeves, 2013; Ipsen \& Andersen, 2013; Nielsen et al., 2013). These interventions emphasise the need for aligning (von Thiele Schwarz \& Hasson, 2013) or fitting (Randall \& Nielsen, 2012; Nielsen et al., 2014) the intervention to the respective organisation where it is implemented. Such non-standardised interventions generate challenges for their evaluation, as both the process and context need to be thoroughly evaluated to understand under what circumstances the interventions are effective for what sub-groups (see also Karanika-Murray \& Biron, 2013). Although capacity-building for future problem solving is not the primary aim of the contingency approach, evaluations should still assess the degree of capacity-building achieved to consider the potential for maintaining long-term, sustainable intervention effects.

\section{OHD Model Guiding Capacity-Building in Practice}

The current state of OHD interventions raises the question of how a configurational, capacity-building approach for OHD can be designed as this approach is expected to have the most profound and long-lasting impact on organisational health. We previously described in detail how we built on the OHD model to develop a capacity-building approach with a broad range of companies in the production, health care and other service sectors and how it can be practically implemented (see Bauer et al., 2014; Hoffmann et al., 2014, Bauer and Jenny). Here, we shortly summarise the key elements.

The OHD model shows that interventions should build up the individual and organisational capacities that influence the job demands and job resources of their employees. Promising ways to obtain the initial buy-in of organisations for such an OHD intervention might be linking the promotion of positive health to the broader corporate agendas of sustainable workability, keeping the ageing workforce engaged, promoting agility and innovativeness of the organisation, being perceived as an attractive employer as well as the desire to show social responsibility and sustainability. Based on an initial, qualitative analysis of the organisational capacities (structure, strategy and culture) and employees' capacities (competency, motivation and identity) as the organisation's initial configuration, external OHD experts develop an intervention architecture together with internal project managers. This intervention architecture defines which intervention elements such as surveys or workshops are implemented with whom in which sequential order. The architecture also considers previous experience and routines with (healthoriented) optimisation processes in the organisation.

As line managers are seen as key change agents within organisations, they typically take part in a workshop where they learn to see and talk about OHD from their perspective and within the logic of their organisation. During joint action planning, they self-experience how to improve their own job demands and resources and are empowered to work with their team on these issues. In team workshops moderated by the line managers themselves, teams follow the format of a solution-oriented 'future workshop' to improve their shared job demands and resources. Participants in these workshops create lists of measures that are targeted at the individual, leader, group/team or organisational levels - thus also influencing individual and organisational capacities. Finally, in refresher sessions, the implementation progress is monitored, and the participants reflect upon their experiences (for details, see Bauer \& Jenny, 2018).

Throughout this process, the OHD model serves as a common mind map and group action theory for all stakeholders, generating a common language, compatible perspectives and mutual action. It supports systemic, multilevel thinking, enabling company members to see their blind spots, helps to reflect on how the organisation impacts their health and raises awareness about the interaction between the organisation and its individual members. Meanwhile, we developed a fully virtual coaching tool for leaders containing all needed instruments including a simplified version of the OHD model as a mind map to go through such capacitybuilding process with their teams (Grimm et al., 2020). 


\section{Capacity-Building for OHD: Relationship to the Salutogenic Model}

Above, we showed that the OHD model is a specification and expansion of the salutogenic model for the context of organisations. We also showed that interventions following this model will build up individual and organisational capacities as key structural resources that will influence both job resources and job demands (stressors) of employees. Thus, this intervention approach directly influences resources and stressors as two key elements of the salutogenic model.

Regarding the third key element of the salutogenic model, the general SOC, Antonovsky (1987a, 1987b) postulated that its three dimensions are built up through specific life experiences: consistency in life will strengthen comprehensibility, an under-/over-load balance will strengthen manageability and participation in socially valued decision-making will strengthen the meaningfulness component of SOC. The capacity-building for OHD strengthens such life experiences as follows:

- Under-lover-load balance/manageability: Building up individual, organisational and job-related resources combined with the targeted reduction of job demands (stressors) directly influences the load balance of employees and thus the perceived manageability of their working life and life in general. As the OHD approach also builds up the capacity to continuously improve the ratio between job demands and resources, it is expected to have a longlasting impact on the load balance.

- Consistency/comprehensibility: Using the OHD model throughout the intervention as a shared frame of reference increases the likelihood that the intervention process itself is perceived as more comprehensible. Also involving leaders and employees in interpreting, prioritising and acting upon their situation-specific key job demands and resources raises the consistency and comprehensibility of the content of the intervention.

- Participation/meaningfulness: The just mentioned involvement of leaders and teams in each stage of the OHD intervention assures high participation, ownership and thus meaningfulness of the intervention. Also, the balanced goal of not only reducing stress and negative health outcomes but also enhancing resources to assure thriving at work makes the intervention more meaningful than one-sided, psychosocial risk management approaches. Finally, the OHD model communicates a shared responsibility of both employers and employees to improve the interaction between individual and organisational capacities in their organisation. This implies a shared responsibility and ownership, and thus meaningful, active roles in OHD.

\section{Conclusions for Future Research and Practice}

Specifying and expanding the general salutogenic model for organisations facilitates the study of both pathogenic and salutogenic health development processes in this context. Such a model-driven approach allows the classification of resources into the more dynamic job resources related to work processes and into individual- and organisational-level capacities as the more stable resources. This clear classification system will allow the systematic, time-sensitive comparative study of the relative influence of both types of resources on work-related SOC, general SOC as well as negative and positive health outcomes.

Regarding intervention research, the OHD model can provide a common group action theory for both researchers and practitioners in this area, facilitating the development of a well-structured, cumulative evidence base and evidencebased practice. Regarding outcome research, the $\mathrm{OHD}$ research model suggests the conducting of a step-wise analysis from changes in job demands and job resources to changes in negative and positive health outcomes, finally leading to changing performance (Jenny et al., 2014). Moreover, the model suggests the assessment of changes of individual and organisational capacities as indicators of more figurational and thus sustainable changes.

Field research regarding capacity-building for OHD in organisations as complex systems will require study designs 'fit for purpose' (Cox et al., 2007), for example, by retrospectively assigning employees to intervention and control groups based on the analysis of who could be reached by an organisation-wide intervention or based on their assessment of the intervention's impact (Jenny et al., 2014; Randall et al., 2005). In addition, it could be advisable to focus such intervention research on teams as smaller, more feasible subunits of analysis and change in organisations (Ipsen et al., 2015; Bauer \& Jenny, 2018). In both cases, a mixed-methods approach will allow researchers to systematically collect and analyse the context, process and outcomes of such comprehensive interventions (Biron \& Karanika-Murray, 2014; Fridrich et al., 2015).

\section{Future Challenges}

One key challenge for promoting salutogenic organisations is the ongoing digital transformation of our economies and societies. New digital technologies will trigger profound changes in organisations, of their products and services, of the way they organise and partly automise work, etc. Digitalisation will also influence how we ourselves will craft our work and private life. On the one hand, all these changes pose pathogenic threats, such as job loss, fragmented jobs, 
being isolated at work or being continuously controlled by big data. On the other hand, they offer salutogenic opportunities for building more self-determined, socially inclusive, equitable societies. Here the OHD model can provide a framework to various stakeholders to reflect upon and purposefully influence the digital transformation in a more health-promoting way.

Another great challenge ahead will be to reflect upon and redefine the role of organisations in society in a profound way. Currently, large parts of society seem to accept that organisations - particularly for-profit corporations - are independent, hardly regulated entities that have the primary purpose of generating profits and that are little accountable to society at large. However, as societies provide stable environments and pre-conditions for the thriving of organisations, they are entitled to demand that organisations directly contribute to the larger aims of society and their members. The concepts of healthy organisations and OHD would require that organisations at least regularly assess and improve both pathogenic and salutogenic processes for the benefit of their members and their larger environment. However, only involving its members and customers in addressing the more fundamental question of why the organisation exists will lead to more purpose-driven, thriving organisations and more sustainable societies in the future.

\section{References}

Antonovsky, A. (1979). Health, stress, and coping. Jossey-Bass.

Antonovsky, A. (1987a). Health promoting factors at work: The sense of coherence. In C. L. Cooper, R. Kalimo, \& M. El-Batawi (Eds.), Psychosocial factors at work and their relation to health (pp. 153167). WHO.

Antonovsky, A. (1987b). Unraveling the mystery of health: How people manage stress and stay well. Jossey-Bass.

Antonovsky, A., \& Sourani, T. (1988). Family sense of coherence and family adaptation. Journal of Marriage and the Family, 50(Feb), 79. https://doi.org/10.2307/352429

Bakker, A. B., \& Demerouti, E. (2007). The job demands-resources model: State of the art. Journal of Managerial Psychology, 22(3), 309-328. https://doi.org/10.1108/02683940710733115

Bakker, A. B., \& Demerouti, E. (2017). Job demands-resources theory: Taking stock and looking forward. Journal of Occupational Health Psychology, 22(3), 273-285. https://doi.org/10.1037/ocp0000056

Bakker, A. B., \& Derks, D. (2010). Positive occupational health psychology. In S. Leka \& J. Houdmont (Eds.), Occupational health psychology (pp. 194-224). Wiley-Blackwell.

Bakker, A. B., \& Schaufeli, W. B. (2008). Positive organisational behavior: Engaged employees in flourishing organisations. Journal of Organizational Behavior, 29(2), 147-154. https://doi.org/10.1002/ job.515

Bauer, G., Davies, J. K., Pelikan, J., \& on behalf of the Euhpid Theory Working Group and The Euhpid Consortium. (2006). The EUHPID Health Development Model for the classification of public health indicators. Health Promotion International, 21(2), 153-159. https:// doi.org/10.1093/heapro/dak002

Bauer, G. F., \& Hämmig, O. (2014). Bridging occupational, organisational and public health: A transdisciplinary approach. In G. F.
Bauer \& O. Hämmig (Eds.), Bridging occupational, organisational and public health (pp. 1-11). Springer.

Bauer, G. F., \& Jenny, G. J. (2012). Moving towards positive organisational health: Challenges and a proposal for a research model of organisational health. In J. Houdmont, S. Leka, \& R. R. Sinclair (Eds.), Contemporary occupational health psychology: Global perspectives on research and practice (pp. 126-145). Wiley.

Bauer, G. F., \& Jenny, G. J. (2013a). From fidelity to figuration: Current and emerging approaches to organisational health intervention research. In G. F. Bauer \& G. J. Jenny (Eds.), Salutogenic organisations and change. The concepts behind organisational health intervention research (pp. 1-16). Springer.

Bauer, G. F., \& Jenny, G. J. (Eds.). (2013b). Salutogenic organisations and change: The concepts behind organisational health intervention research. Springer.

Bauer, G. F., \& Jenny, G. J. (2018). Leadership and team development to improve organisational health. In K. Nielsen \& A. Noblet (Eds.), Organizational interventions for health and Well-being: A handbook for evidence-based practice (pp. 237-261). Routledge.

Bauer, G. F., Lehmann, K., Blum-Rüegg, A., \& Jenny, G. J. (2014). Systemic consulting for organisational health development: Theory and practice. In G. F. Bauer \& O. Hämmig (Eds.), Bridging ocсиpational, organisational and public health (pp. 117-132). Springer.

Bennett, J. B., Cook, R. F., \& Pelletier, K. R. (2002). Toward an integrated framework for comprehensive organisational wellness: Concepts, practices, and research in workplace health promotion. In L. E. Tetrick (Ed.), Handbook of occupational health psychology. American Psychological Association.

Biron, C., \& Karanika-Murray, M. (2014). Process evaluation for organisational stress and wellbeing interventions: Implications for theory, method, and practice. International Journal of Stress Management, 21(1), 85-111. https://doi.org/10.1037/a0033227

Bond, F. W., Flaxman, P. E., \& Loivette, S. (2006). A business case for the management standards of stress. HSE research report 431. HSE Books.

Brauchli, R., Jenny, G. J., Füllemann, D., \& Bauer, G. F. (2015). Towards a job demands-resources health model: Empirical testing with generalisable indicators of job demands, job resources, and comprehensive health outcomes. BioMed Research International. https://doi.org/10.1155/2015/959621

Cameron, K. S., Dutton, J. E., \& Quinn, R. E. (2003). Positive organisational scholarship. Berrett-Koehler.

Cilliers, F. (2011). Individual diversity management and salutogenic functioning. International Review of Psychiatry, 23(6), 501-507. https://doi.org/10.3109/09540261.2011.637911

Cilliers, F., \& Kossuth, S. (2002). The relationship between organisational climate and salutogenic functioning. SA Journal of Industrial Psychology, 28(1), 8-13. https://doi.org/10.4102/sajip.v28i1.42

Cotton, P., \& Hart, P. M. (2003). Occupational wellbeing and performance: A review of organisational health research. Australian Psychologist, 38(2), 118-127. Retrieved from http://www.informaworld.com/10.1080/00050060310001707117.

Cox, T., Karanika, M., Griffiths, A., \& Houdmont, J. (2007). Evaluating organisational-level work stress interventions: Beyond traditional methods. Work \& Stress, 21(4), 348-362. https://doi. org/10.1080/02678370701760757

Day, A., \& Randell, K. D. (2014). Building a foundation for psychologically healthy workplaces and wellbeing. In A. Day, E. K. Kelloway, \& J. J. Hurrell (Eds.), Workplace wellbeing. How to build psychologically healthy workplaces (pp. 3-26). Chichester.

DeJoy, D. M., \& Wilson, M. G. (2003). Organisational health promotion: Broadening the horizon of workplace health promotion. American Journal of Health Promotion, 17(5), 337-341.

Delery, J. E., \& Doty, D. H. (1996). Modes of theorising in strategic human resource management: Tests of universalistic, contingency, and configurational performance predictions. The Academy of 
Management Journal, 39(4), 802-835. Retrieved from http://www. jstor.org/stable/256713.

Eberz, S., \& Herbert Antoni, C. (2016). Das SystemischSalutogene Interaktions-Modell (SSIM) - Ein ganzheitlicher Ansatz zur Erklärung und Entwicklung gesundheitsförderlicher Interaktionsdynamiken zwischen Führungskräften und Mitarbeitenden. Gruppe. Interaktion. Organisation. Zeitschrift Für Angewandte Organisationspsychologie (GIO), 47(3), 265-273. https://doi.org/10.1007/s11612-016-0326-6

Feldt, T., Kinnunen, U., \& Mauno, S. (2000). A mediational model of sense of coherence in the work context: A one-year follow-up study. Journal of Organizational Behavior, 21(4), 461-476. https://doi.org/10.1002/ (SICI)1099-1379(200006)21:4<461::AID-JOB11>3.0.CO;2-T

Fredrickson, B. L. (2003). Positive emotions and upward spirals in organisations. In K. Cameron, J. Dutton, \& R. Quinn (Eds.), Positive organisational scholarship (pp. 163-175). Berrett-Koehler.

Fredrickson, B. L., \& Dutton, J. E. (2008). Unpacking positive organising: Organisations as sites of individual and group flourishing. The Journal of Positive Psychology, 3(1), 1-3. https://doi. org/10.1080/17439760701750964

Fridrich, A., Jenny, G. J., \& Bauer, G. F. (2015). The context, process, and outcome evaluation model for organisational health interventions. BioMed Research International. https://doi. org/10.1155/2015/414832

Giddens, A. (1984). The constitution of society, outline of the theory of structuration. Polity Press.

Gilbert, S., \& Kelloway, E. K. (2014). Positive psychology and the healthy workplace. In A. Day, E. K. Kelloway, \& J. J. Hurrell (Eds.), Workplace wellbeing. How to build psychologically healthy workplaces (pp. 50-71). Chichester.

Graeser, S. (2011). Salutogenic factors for mental health promotion in work settings and organisations. International Review of Psychiatry, 23(6), 508-515. https://doi.org/10.3109/09540261.2011.637909

Grawitch, M. J., Gottschalk, M., \& Munz, D. C. (2006). The path to a healthy workplace: A critical review linking healthy workplace practices, employee wellbeing, and organisational improvements. Consulting Psychology Journal Practice and Research, 58(3), 129_ 147. https://doi.org/10.1037/1065-9293.58.3.129

Grimm, A. L., Bauer, G. F., \& Jenny, G. J. (2020, in print). A digital tool to build the capacity of leaders to improve working conditions related to psychological health and wellbeing in teams: Intervention approach, prototype, and evaluation design of the webapplication 'wecoach.' Frontiers in Digital Public Health. https:// doi.org/10.3389/fpubh.2020.521355

Hart, P. M., \& Cooper, C. L. (2001). Occupational stress: Toward a more integrated framework. In D. S. N. Anderson \& H. K. S. Ones (Eds.), Handbook of industrial, work and organisational psychology (Vol. 2, pp. 93-114). Sage.

Henning, R. A., \& Reeves, D. W. (2013). An integrated health protection/promotion program supporting participatory ergonomics and salutogenic approaches in the design of workplace interventions. In G. F. Bauer \& G. J. Jenny (Eds.), Salutogenic organisations and change (pp. 307-325). Springer. https://doi. org/10.1007/978-94-007-6470-5_17

Hoffmann, S., Jenny, G. J., \& Bauer, G. F. (2014). Capacity building as a key mechanism of organisational health development. In G. F. Bauer \& O. Hämmig (Eds.), Bridging occupational, organisational and public health (pp. 103-116). Springer.

Hofmann, D. A., \& Tetrick, L. E. (2003). The etiology of the concept of health: Implications for 'organising' individual and organisational health. In L. E. Tetrick (Ed.), Health and safety in organisations: A multilevel perspective (pp. 1-26). Jossey-Bass.

Ipsen, C., \& Andersen, V. (2013). A multilevel and participatory model of prevention of work-related stress in knowledge work. In G. F. Bauer \& G. J. Jenny (Eds.), Salutogenic organisations and change: The concepts behind organisational health intervention research (pp. 127-148). Springer. https://doi. org/10.1007/978-94-007-6470-5_8

Ipsen, C., Poulsen, S., \& Jenny, G. J. (2015). Editorial: New ideas and insights into designing and understanding effective and sustainable interventions. International Journal of Human Factors and Ergonomics, 3(3/4), 229-234.

Jaffe, D. T. (1995). The healthy company: Research paradigms for personal and organisational health. In S. L. Sauter \& L. R. Murphy (Eds.), Organisational risk factors for job stress (pp. 13-39). American Psychological Association. https://doi. org/10.1037/10173-001

Jenny, G. J., \& Bauer, G. F. (2013). The limits of control: A systemic, model-based approach to changing organisations towards better health. In G. F. Bauer \& G. J. Jenny (Eds.), Salutogenic organisations and change: The concepts behind organisational health intervention research (pp. 167-187). Springer. https://doi. org/10.1007/978-94-007-6470-5_10

Jenny, G. J., Bauer, G. F., Füllemann, D., Broetje, S., \& Brauchli, R. (2020). "Resources-demands ratio": Translating the JD-R-model for company stakeholders. Journal of Occupational Health, 62(1), 1348-9585.12101. https://doi.org/10.1002/1348-9585.12101

Jenny, G. J., Brauchli, R., Inauen, A., Fullemann, D., Fridrich, A., \& Bauer, G. F. (2014). Process and outcome evaluation of an organisational-level stress management intervention in Switzerland (pp. 1-13). Health Promotion International. https://doi.org/10.1093/ heapro/dat091

Jenny, G. J., Inauen, A., Brauchli, R., Füllemann, D., Müller, F., \& Bauer, G. F. (2011). Projekt SWiNG-Schlussbericht der Evaluation [Project SWiNG-Final report of the evaluation]. Retrieved from www.gesundheitsfoerderung.ch/swing

Johnson, S. S., Spehr, M., Rowan, R., Berghoff, J., Kelley, J., \& Sisodia, R. (2019). Editor's desk: The potential and promise of purposedriven Organisations. American Journal of Health Promotion, 33(6), 958-973. https://doi.org/10.1177/0890117119855446

Kaplan, R. S., \& Norton, D. P. (1996). Using the balanced scorecard as a strategic management system. Harvard Business Review, 74(1), 75-85. Retrieved from http://search.ebscohost.com/login.aspx?dire $\mathrm{ct}=$ true $\& \mathrm{db}=$ buh $\& \mathrm{AN}=9601185348 \&$ site $=$ ehost-live .

Karanika-Murray, M., \& Biron, C. (2013). The nature of change in organisational health interventions: Some observations and propositions. In G. F. Bauer \& G. J. Jenny (Eds.), Salutogenic organisations and change (pp. 239-258). Springer. https://doi. org/10.1007/978-94-007-6470-5_13

Kelloway, E. K., \& Day, A. L. (2005). Building healthy workplaces: What we know so far. Canadian Journal of Behavioral Science, 37, 223-235. https://doi.org/10.1037/h0087259

Kerr, R., McHugh, M., \& McCrory, M. (2009). HSE management standards and stress-related work outcomes. Occupational Medicine, 59(8), 574-579. https://doi.org/10.1093/occmed/kqp146

Kossuth, S. P., \& Cilliers, F. (2002). The relationship between leadership dimensions, cultural beliefs and salutogenic functioning. South African Journal of Labour Relations, 26(1), 65-95.

Krafft, A. (2012). The Management of Innovations and Personal Well-being: A trans-disciplinary model and empirical findings. In Systemic Management for Intelligent Organizations (pp. 99-119). Springer.

Luhmann, N. (1984). Soziale Systeme. Grundriss einer allgemeinen Theorie. [Social Systems]. Suhrkamp.

Luthans, F., \& Church, A. H. (2002). Positive organisational behavior: Developing and managing psychological strengths. Academy of Management Executive, 16(1), 57-72. https://doi.org/10.5465/ AME.2002.6640181

Maak, T., \& Ulrich, P. (2007). Integre Unternehmensführung: Ethisches Orientierungswissen für die Wirtschaftspraxis. Schäffer-Poeschel.

Mayer, C. H., \& van Zyl, L. E. (2013). Perspectives of female leaders on sense of coherence and mental health in an engineering environ- 
ment. SA Journal of Industrial Psychology, 39(2 SPL), 1-11. https:// doi.org/10.4102/sajip.v39i2.1097

Muller, Y., \& Rothmann, S. (2009). Sense of coherence and employees' perceptions of helping and restraining factors in an organisation. SA Journal of Industrial Psychology, 35(1). https://doi.org/10.4102/ sajip.v35i1.731

Nelson, D. L., \& Cooper, C. L. (2008). Positive organisational behavior: An inclusive view. In D. L. Nelson \& C. L. Cooper (Eds.), Positive organisational behavior. Sage.

NHS. (2009). Organisational health: A new perspective on performance improvement? NHS.

Nielsen, K., Abildgaard, J. S., \& Daniels, K. (2014). Putting context into organisational intervention design: Using tailored questionnaires to measure initiatives for worker wellbeing. Human Relations, 67(12), 1537-1560. https://doi.org/10.1177/0018726714525974

Nielsen, K., Stage, M., Abildgaard, J. S., \& Brauer, C. V. (2013). Participatory intervention from an organisational perspective: Employees as active agents in creating a healthy work environment. In G. F. Bauer \& G. J. Jenny (Eds.), Salutogenic organisations and change (pp. 327-350). Springer. https://doi. org/10.1007/978-94-007-6470-5_18

Peiró, J. M. (2000). Assessment of psychosocial risks and prevention strategies: The amigo model as the basis of the prevenlab/psicosocial methodology. Psychology in Spain, 4(1), 139-166. Retrieved from http://dialnet.unirioja.es/servlet/articulo?codigo=960634\&inf $\mathrm{o}=$ resumen\&idioma $=\mathrm{ENG}$

Peiró, J. M., \& Rodríguez, I. (2008). Work stress, leadership and organizational health. Papeles Del Psicologo, 29(1), 68-81.

Quick, J. C., Macik-Frey, M., \& Cooper, C. L. (2007). Managerial dimensions of organisational health: The healthy leader at work. Journal of Management Studies, 44(2), 189-205. https://doi. org/10.1111/j.1467-6486.2007.00684.x

Randall, R., Griffiths, A., \& Cox, T. (2005). Evaluating organisational stress-management interventions using adapted study designs.
European Journal of Work and Organizational Psychology, 14(1), 23-41.

Randall, R., \& Nielsen, K. (2012). Does the intervention fit? An explanatory model of intervention success and failure in complex organisational environments. In C. Biron, M. Karanika-Murray, \& C. L. Cooper (Eds.), Improving organisational interventions for stress and ... (pp. 120-135). Routledge.

Rüegg-Stürm, J. (2003). Das Neue St. Galler management-Modell: Grundkategorien einer integrierten Managementlehre. Der HSG-ansatz. [the new management model of St. Gallen: Basic dimensions for integrated management studies. The HSG-approach] (2nd ed.). Paul Haupt.

Salanova, M., Llorens, S., Cifre, E., \& Martinez, I. M. (2012). We need a hero! Toward a validation of the healthy and resilient organisation (HERO) model. Group \& Organization Management, 37(6), 785-822. https://doi.org/10.1177/1059601112470405

Shoaf, C., Genaidy, A., Karwowski, W., \& Huang, S. H. (2004). Improving performance and quality of working life: A model for organisational health assessment in emerging enterprises. Human Factors and Ergonomics in Manufacturing, 14(1), 81-95. https:// doi.org/10.1002/hfm.10053

von Thiele Schwarz, U., \& Hasson, H. (2013). Alignment for achieving a healthy organisation. In G. F. Bauer \& G. J. Jenny (Eds.), Salutogenic organisations and change: The concepts behind organisational health intervention research (pp. 107-125). Springer. https://doi.org/10.1007/978-94-007-6470-5_7

WHO. (1998). Health promotion glossary. WHO.

WHO. (2010). WHO healthy workplace framework and model: Background and supporting literature and practice. WHO. Retrieved from http://www.who.int/occupational_health/healthy_workplace_ framework.pdf.

Zwetsloot, G., Leka, S., \& Jain, A. (2008). Corporate social responsibility \& psychosocial risk management. In S. Leka \& T. Cox (Eds.), The European framework for psychosocial risk management: PRIMA-EF (pp. 96-114). I-WHO.

Open Access This chapter is licensed under the terms of the Creative Commons Attribution 4.0 International License (http://creativecommons. org/licenses/by/4.0/), which permits use, sharing, adaptation, distribution and reproduction in any medium or format, as long as you give appropriate credit to the original author(s) and the source, provide a link to the Creative Commons license and indicate if changes were made.

The images or other third party material in this chapter are included in the chapter's Creative Commons license, unless indicated otherwise in a credit line to the material. If material is not included in the chapter's Creative Commons license and your intended use is not permitted by statutory regulation or exceeds the permitted use, you will need to obtain permission directly from the copyright holder. 